\title{
Two lineage boundaries coordinate vertebrate apical ectodermal ridge formation
}

\author{
Robin A. Kimmel, ${ }^{1,2}$ Daniel H. Turnbull, ${ }^{3}$ Veronique Blanquet, ${ }^{4,5}$ Wolfgang Wurst, ${ }^{4,5}$ \\ Cynthia A. Loomis, ${ }^{1,6}$ and Alexandra L. Joyner ${ }^{1,2,7,8}$

\begin{abstract}
${ }^{1}$ Department of Cell Biology; ${ }^{2}$ Howard Hughes Medical Institute and Developmental Genetics Program, Skirball Institute of Biomolecular Medicine; ${ }^{3}$ Department of Radiology and Pathology and Skirball Institute of Biomolecular Medicine, New Neurogenetics, 80804 Munich, Germany; ${ }^{5}$ GSF-Research Center, Institute for Mammalian Genetics, 85764 Oberschleissheim, Germany; ${ }^{6}$ Ronald O. Perelman Department of Dermatology and ${ }^{7}$ Department of Physiology and
\end{abstract} \\ York University School of Medicine, New York, New York 10016 USA; ${ }^{4}$ Max Planck Institute of Psychiatry, Clinical \\ Neuroscience, New York University School of Medicine, New York, New York 10016 USA
}

\begin{abstract}
Proximal-distal outgrowth of the vertebrate limb bud is regulated by the apical ectodermal ridge (AER), which forms at an invariant position along the dorsal-ventral (D/V) axis of the embryo. We have studied the genetic and cellular events that regulate AER formation in the mouse. In contrast to implications from previous studies in chick, we identified two distinct lineage boundaries in mouse ectoderm prior to limb bud outgrowth using a Cre/loxP-based fate-mapping approach and a novel retroviral cell-labeling technique. One border is transient and at the limit of expression of the ventral gene En1, which corresponds to the D/V midline of the AER, and the second border corresponds to the dorsal AER margin. Labeling of AER precursors using an inducible Cre showed that not all cells that initially express AER genes form the AER, indicating that signaling is required to maintain an AER phenotype. Misexpression of En1 at moderate levels specifically in the dorsal AER of transgenic mice was found to produce dorsally shifted AER fragments, whereas high levels of En1 abolished AER formation. In both cases, the dorsal gene Wnt7a was repressed in cells adjacent to the En1-expressing cells, demonstrating that signaling regulated by EN1 occurs across the D/V border. Finally, fate mapping of AER domains in these mutants showed that En1 plays a part in positioning and maintaining the two lineage borders.
\end{abstract}

[Key words: AER; boundary; En1; Engrailed1; limb; mouse]

Received February 24, 2000; revised version accepted April 4, 2000.

The coordinated activity of factors expressed in specific localized domains patterns the limbs along three asymmetric axes. A multilayered columnar epithelium, called the apical ectodermal ridge (AER), forms at what is thought to be the junction between dorsal and ventral ectoderm and produces growth factors that promote proximal-distal outgrowth. Signals from the presumptive limb mesenchyme are required to induce an AER, whereas signaling within the ectoderm apparently directs positioning and maturation of the AER (Irvine and Vogt 1997; Niswander 1997; Zeller and Duboule 1997). Although mesodermal signaling molecules that can activate AER gene expression have been identified (Min et al. 1998; Sekine et al. 1999), the process of ridge assembly and localization is less well understood and only few molecules involved have been identified (Tickle and Altabef 1999).

${ }^{8}$ Corresponding author.

E-MAIL joyner@saturn.med.nyu.edu; FAX (212) 263-7760 or (212) 2630614.
During Drosophila appendage formation, interactions at boundaries between cells of differentially specified domains leads to the formation of specialized signaling centers that generate proximal-distal outgrowth. It has been hypothesized that a limb ectoderm dorsal-ventral $(\mathrm{D} / \mathrm{V})$ boundary exists that is analogous to the imaginal disc compartment border and is important for AER development (Irvine and Vogt 1997; Niswander 1997; Zeller and Duboule 1997; Loomis et al. 1998; Martin 1998; Tickle and Altabef 1999). The relevance of such a boundary for AER formation was supported by the observation that ectopic limbs induced by FGF beads implanted into the interlimb flank region develop in precise alignment with the normal limbs /Cohn et al. 1995; Crossley et al. 1996; Vogel et al. 1996; Altabef et al. 1997). In addition, transplant and dye labeling experiments in chick provided evidence for compartments within limb ectoderm, but the two experimental approaches identified different potential borders in the AER (Altabef et al. 1997; Michaud et al. 1997). Chickquail transplants showed a lineage restriction in the mid- 
line of the AER when dorsal and ventral tissues were apposed, whereas dye labeling experiments showed dorsally and ventrally derived cells mixing within the AER, although cells never crossed into the opposing ectoderm domain (Altabef et al. 1997; Michaud et al. 1997). The different results obtained in these two studies have not been reconciled and may be due to differences in the cell-labeling techniques and analysis with respect to region and time.

Unlike the direct induction of signaling centers along compartment boundaries in Drosophila, formation of the mature AER appears to involve the convergence of broadly distributed precursor cells towards the dorsalventral D/V boundary of the limb field (Altabef et al. 1997; Martin 1998). Chick-quail transplantation studies have indicated that cells giving rise to the mature AER are initially located in a broad region of $\mathrm{D} / \mathrm{V}$ ectoderm just prior to the formation of a thickened ridge (Michaud et al. 1997). Consistent with this, in mouse, AER marker gene expression is initially observed in a broad domain of thickened ventral ectoderm (the pre-AER) and progressively becomes restricted to the triangular AER at the distal margin (Milaire 1974; Crossley and Martin 1995; Mahmood et al. 1995; Bell et al. 1998; Loomis et al. 1998). Studies using diI labeling, however, showed mixing of AER precursors with cells destined to be non-AER ectoderm prior to limb outgrowth (Altabef et al. 1997). Lineage analysis is necessary to establish whether there is a distinct population of committed AER precursors (Tickle and Altabef 1999).

Clues that distinctly specified dorsal and ventral limb domains play a role in AER formation have come from the finding that some molecules expressed in restricted domains along the $\mathrm{D} / \mathrm{V}$ axis of the limb are required for proper AER morphology in addition to $\mathrm{D} / \mathrm{V}$ patterning. Dorsal ectoderm expresses the secreted factor WNT7A, which promotes dorsal-type differentiation through induction of the transcription factor LMX1B in the underlying mesenchyme (Riddle et al. 1995; Vogel et al. 1995). Loss of Wnt7a or $L m x 1 b$ function leads to double ventral paws or limbs, respectively (Parr and McMahon 1995; Chen et al. 1998). However, there is apparently no effect on AER development in these mutants (Parr and McMahon 1995; Chen et al. 1998). Furthermore, Wnt7a or Lmx1b misexpression did not disrupt AER formation (Riddle et al. 1995; Vogel et al. 1995). The homeobox transcription factor EN1 is expressed in the ventral ectoderm and the ventral half of the AER (Davis et al. 1991; Loomis et al. 1996). Loss of En1 function results in ectopic Wnt7a expression in the ventral ectoderm and subsequently the limbs show a loss of ventral differentiation distally and ectopic formation of dorsal structures ventrally (Loomis et al. 1996). In addition, the AER fails to develop normally in En1 mutants, with AER genes continuing to be expressed in a broad region similar to the pre-AER instead of in a narrow domain. The most striking consequence of this AER abnormality is the formation of ectopic AERs, which give rise to extra ventral digits. Significantly, the ectopic AERs are located adjacent to, and are dependent on, the ectopic Wnt7a expres- sion seen in En1 null mutants (Loomis et al. 1996; Cygan et al. 1997; Loomis et al. 1998). Curiously, ectopic expression of En1 randomly within large regions of the limb bud results in both inhibition and induction of AERs (Laufer et al. 1997; Logan et al. 1997; RodriguezEsteban et al. 1997). It is evident from these studies that En1, and possibly Wnt7a, are involved in AER formation, but how En1 acts is not clear.

To determine whether specific boundaries exist within the AER, we have used a Cre/LoxP-based fatemapping approach and a retroviral cell-marking technique. A lineage boundary that prevents mixing of AER cells with the adjacent ectoderm was identified at the dorsal margin of the AER from before the time of limb bud outgrowth at $9.5 \mathrm{dpc}$. A second lineage restriction that corresponds to the middle of the AER (D/V border) and the distal limit of En1 expression was observed prior to and during AER formation. This provides a basis for distinct ventral versus dorsal identities within the developing AER to play an early role in its proper formation and positioning. To test whether En1 regulates boundary stability and/or D/V signaling within the AER, En1 was specifically misexpressed in the dorsal AER of transgenic mice using an $M s \times 2$ promoter. Fate mapping in these Msx2-En1 mutants showed that the dorsal and D/V AER boundaries were not properly established and developed jagged contours. Moderate levels of En1 in the dorsal AER led to fragmented and displaced ridges, whereas high levels abolished AER formation. Furthermore, Wnt7a expression was repressed in cells adjacent to the ectopic En1 dorsal AER domain. Taken together, our fate mapping and misexpression studies demonstrate that limb ectoderm is divided by two, rather than one, compartment borders, and that signaling across these borders is critical for AER formation. We propose a model for AER formation in which signaling at the dorsal AER border, and downstream of En1 at the D/V border, are involved in directing movement of pre-AER cells and maintenance of AER gene expression to form the mature compacted ridge at its proper location.

\section{Results}

En1 Expressing cells respect a transient lineage restriction in the $A E R$

A recently developed Cre/loxP system was used to examine whether En1-expressing cells are restricted from crossing the D/V boundary of the AER (Zinyk et al. 1998). This approach involves expressing a site-specific recombinase transiently in specific cells, which induces a recombination event that leads to permanent expression of lacZ. The distribution of the marked cells and their progeny can then be detected at subsequent stages. Mice expressing Cre recombinase from an En1 knock-in allele $\left(E n 1^{C k i}\right)$ (Hanks et al. 1995) were bred with a universal lacZ reporter mouse strain (called R26R; Soriano 1999) and lacZ-expressing cells were examined at embryonic stages (Fig. 1A).

lacZ expression could be detected in En1 ${ }^{\mathrm{Cki}}{ }_{;} \mathrm{R} 26 \mathrm{R}$ 

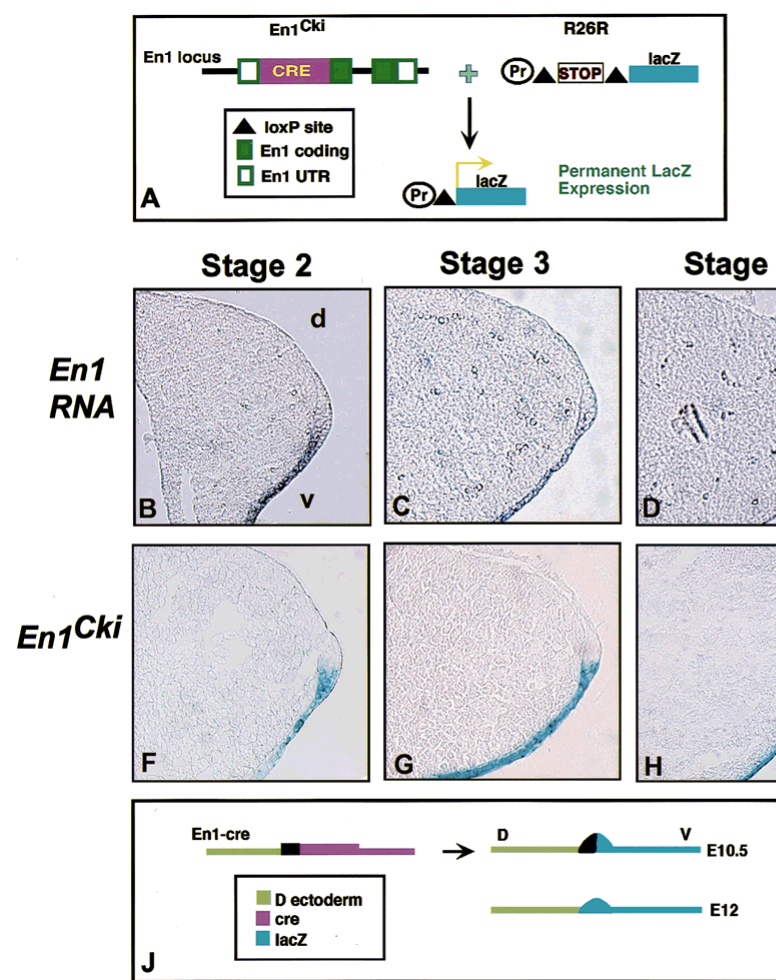

Figure 1. A D/V lineage border corresponds to the distal limit of En1 expression. (A) Schematic showing the fate-mapping approach used with Cre/LoxP. In En1 ${ }^{\text {Cki }}$ (top left), Cre recombinase replaces part of the En1 coding sequence. The R26R reporter allele (top right) consists of a loxPstop-loxP cassette inserted upstream of the lacZ gene in the Rosa26 locus. In En1-expressing cells of mice heterozygous for both $E n 1^{C k i}$ and R26R, the Cre excises the stop sequence, resulting in constitutive lac $Z$ production. $(B-E)$ Whole-mount RNA insitu hybridization with an En1 probe, followed by cryosection at 6-8 $\mu \mathrm{m}$. En1 is expressed in the ventral ectoderm and ventral half of the pre-AER in a stage $2 \mathrm{limb}$ bud $(B)$ and at stage 3 in the ventral ectoderm and ventral half of the mature AER (C). At stage $4(11.5 \mathrm{dpc})(D)$ and later, expression becomes apparent in the dorsal portion of the ridge, which is flattened by stage $6(E) .(F-I)$ Embryos heterozygous for both En1 ${ }^{C k i}$ and R26R stained for $\beta$-galactosidase activity, followed by cryosectioning at 6-8 $\mu \mathrm{m}$. Cells positive for lac $Z$ are found in the ventral ectoderm and the ventral part of the developing $(F)$ and mature $(G)$ AER up to stage 3. At stage $4(H)$ and later $(I)$, lacZ staining is seen in the dorsal portion of the ridge. (J) Schematic showing that at $10.5 \mathrm{dpc}$, En1-Cre-activated lacZ is seen only up to the D/V midline of the ridge (top right). After $11.5 \mathrm{dpc}$, blue cells are also seen in the dorsal portion of the flattened ridge (bottom right).

double transgenic limb buds as early as stage 1 (E9.5) in the ventral ectoderm and pre-AER. Prior to stage 4 (11.5 dpc), En $1^{C k i} ;$ R26R double transgenic embryos expressed lacZ in the ventral ectoderm and specifically within only the ventral portion of the AER (Fig. 1F,G). Because lacZ marks all cells that have previously expressed En1, these results demonstrate that En1-expressing cells are restricted from crossing a boundary in the middle of the AER. However, double transgenic embryos examined at stage 4 were found to have some lacZ-expressing cells in the dorsal portion of the AER (Fig. 1H). At later stages, as the ridge morphology flattened, it became more difficult to determine where the $\mathrm{D} / \mathrm{V}$ border within the AER was located. Nevertheless, lac $Z$ was expressed throughout the thickened remnant of the ridge (Fig. 1I). Examination of En1 expression between stage $2(10.0 \mathrm{dpc})$ and stage 6 $(12.5 \mathrm{dpc})$ showed that En1 RNA was detected in the ventral ectoderm and ventral AER prior to stage 4 (Fig. $1 \mathrm{~B}, \mathrm{C})$ but was also present in the dorsal AER at later stages (Fig. 1D,E). Thus, it is not certain whether dorsal AER cells initiate En1 expression after stage 4 or if dorsal AER cells are lost.

To provide further evidence for a lineage restriction within the AER that was independent of possible changes in gene expression, we performed a lineage analysis using ultrasound backscatter microscopy (UBM) to guide retroviral infection of limb ectoderm (Liu et al. 1998; Gaiano et al. 1999). A replication-defective lacZexpressing retrovirus, pNK-lacZ (Gaiano et al. 1996), was injected into the amniotic fluid of wild-type em- bryos in utero at $8.5 \mathrm{dpc}$ (prior to limb bud outgrowth), allowing surface ectoderm cells to be randomly infected and transmit lacZ expression to their descendants. Two or three days later, embryos were harvested and stained with X-gal. The level of infection varied greatly between embryos, with some being densely covered with blue cells and others having only a few scattered patches. The dispersal of the clustered cells on lightly infected embryos varied according to location within the limb bud. Patches of cells found proximally tended to be loosely associated and irregularly shaped (Fig. 2E, yellow oval). By contrast, tightly clustered cells were found within the AER, appearing to align along the margin (Fig. 2A,E, red box).

For our analyses, we chose only embryos with few cell clusters in the limbs that included clusters aligned along the distal limb margin separated from other blue cells by $\sim 10$ cell diameters or more. Because lipophilic dye labeling experiments in chick have shown that extensive cellular rearrangements do not occur in the AER (Vargesson et al. 1997) and retroviral infection of mouse ectoderm at $9.0 \mathrm{dpc}$ has shown that the progeny of infected cells remain in cohesive clusters (Sanes et al. 1986), the discrete cell clusters examined were assumed to be the progeny of a single or at most two infected parent cells. Limbs containing clusters of 6 cells or more (average of 8) were sectioned along the $\mathrm{D} / \mathrm{V}$ axis of the limb bud to determine the distribution of cells with respect to the AER. lacZ-expressing AER cells in embryos dissected at 10.5 dpc (limb stages 2-3) were in all but one case (8/9 clus- 
ters) found in either the ventral or the dorsal AER but not in both, consistent with the $E n 1^{C k i}$ fate-mapping studies (Fig 2B-D). To determine whether the lineage restriction was lost at later stages of development, embryos were collected at $11.5 \mathrm{dpc}$ (limb stages 4-5) and discrete clusters containing an average of 8 cells were examined. Half the clusters $(5 / 10)$ at this stage had cells distributed in both the dorsal and ventral AER (Fig. 2F,G). These results provide further evidence for a lineage restriction at the D/V border of the AER that is only transient and not maintained past $11.5 \mathrm{dpc}$ (Fig. 1J). The presence of this border during AER formation and the fact that loss of the border correlates with degeneration of the AER indicates that such a lineage restriction might be critical for AER morphology.

\section{AER cells respect an additional dorsal boundary}

A further unexpected finding was that in the retrovirally marked cell clusters examined, cells were generally found only within the AER and not also in the neighboring ectoderm. In a few exceptions, cells were seen in immediately adjacent ventral ectoderm (3/13) (Fig. 2H), and in one case in dorsal ectoderm (1/9). This suggested that additional borders might be present between the AER and the adjacent ectoderm domains. To investigate this possibility further, we used the Cre/LoxP system to label cells of the developing pre-AER or AER and follow their distribution with time. AER-specific gene expression was achieved using a fragment of the Msx2 promoter (Liu et al. 1994). Because this promoter is active over an extended time period of limb development, we used an inducible form of Cre (CreER ${ }^{\mathrm{T}}$ ) (Feil et al. 1996; Brocard et al. 1997), which enabled us to modulate the time of initiation and the duration of Cre activity. Fusion proteins of a Cre recombinase and a tamoxifen-responsive estrogen receptor ligand-binding domain $\left(\mathrm{ER}^{\mathrm{T}}\right)$ can be activated in embryos by administering tamoxifen (tam) to the pregnant female following mating between a Cre transgenic and lacZ reporter mouse (Danielian et al. 1998). In control experiments, we found two injections of tam, at doses of up to $10.0 \mathrm{mg}$ each within $12 \mathrm{hr}$ of each other, caused no lethality. Furthermore, a dose of
$5.0 \mathrm{mg}$ generated robust reporter gene expression with Cre in an active state for a maximum of $24 \mathrm{hr}$.

Of nine transgenic founders produced with the Msx2$C r e E R^{T}$ transgene (Fig. 3J), eight transmitted the transgene, and four expressed $C r e E R^{T}$ in the AER, as determined by RNA in situ hybridization. The expression initiated at $9.5 \mathrm{dpc}$ in the forelimbs and $10.0 \mathrm{dpc}$ in the hindlimbs (stage $0.5 / 1$ ) broadly in the ventral ectoderm and with development expression became restricted to the distal margin (Fig. 3A-C). The remaining studies were performed using one line (no. 27) that showed the strongest expression.

To examine the behavior of pre-AER cells with respect to the dorsal and ventral borders of the AER, $5.0 \mathrm{mg}$ of tam was administered at $9.5 \mathrm{dpc}$, as expression of the transgene is initiating in the forelimbs and prior to initiation in the hindlimbs. The hindlimbs of embryos stained for lacZ $\sim 30-36 \mathrm{hr}$ following tam treatment (stage 2, $10.5 \mathrm{dpc}$ ) showed scattered blue staining in the ventral ectoderm and dense labeling in a broad band at the distal margin (Fig. 3D). In embryos treated with tam at $9.5 \mathrm{dpc}$ and collected around 54-60 hr later (stage 4, $11.5 \mathrm{dpc}$ ), there was dense labeling of the narrow AER in hindlimbs, with additional scattered blue cells throughout the ventral ectoderm (Fig. 3E). The dorsal boundary of lacZ-expressing cells was clearly delineated at the dorsal edge of the AER at both stage 2 (10.5 dpc) and stage 4 (11.5 dpc) (Fig. 3D,F, arrow), whereas the ventral boundary was not, with blue cells extending proximally from the distal margin (Fig. 3D,E). Forelimbs showed a similar pattern of lac $Z$ expression with the scattered ventral blue cells being located more distally. These results demonstrate that there is a restriction to cell movement at the dorsal limit of the AER from at least the beginning of formation of the pre-AER, whereas the ventral AER boundary is not determined at $9.5 \mathrm{dpc}$. The one case in the retroviral cell-marking studies in which a dorsal AER cluster extended into the dorsal ectoderm could reflect a polyclone or that the dorsal lineage restriction is not complete at $8.5 \mathrm{dpc}$. Interestingly, the presence of labeled pre-AER cells remaining in the ventral ectoderm following AER formation indicates that the initially specified population of AER precursors that express AER

Figure 2. Retroviral cell labeling delineates a transient early D/V AER boundary. UBM-guided injection of pNK-lacZ into the amniotic sac of wild-type $8.5 \mathrm{dpc}$ embryos, followed by dissection at $10.5 \mathrm{dpc}(A-D)$ or $11.5 \mathrm{dpc}(E-H)$, and staining for $\beta$-galactosidase activity. ( $A, E$, red boxes) $\beta$-galactosidase-stained forelimbs from injected embryos showing tightly clustered cells in the AER, representative of those chosen for cryosectioning. Loosely grouped cells are seen on more proximal regions of the handplate (E, yellow oval). $(B-D)$ Sections along the $\mathrm{D} / \mathrm{V}$ axis of limbs from embryos collected at $10.5 \mathrm{dpc}$ showing cells restricted to either the dorsal $(B, C)$ or the ventral $(D)$ portion
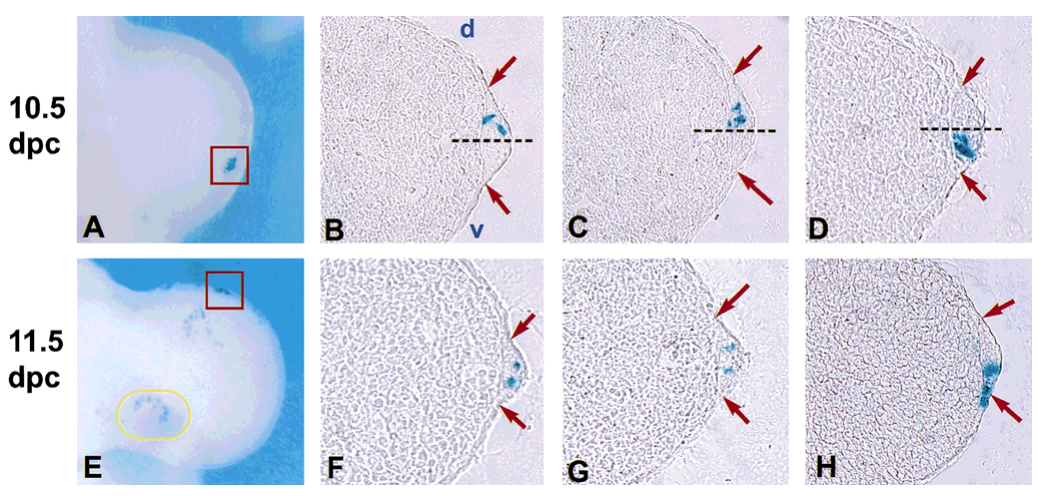

of the AER. (Dashed line) midline; (red arrows) AER margins. Sections of limbs from 11.5-dpc embryos, with cells found in both the dorsal and ventral portions of the AER $(F, G)$. In rare cases, cells were found in the AER and adjacent ventral ectoderm $(H)$. In all sections, distal is to the right and dorsal is up. 


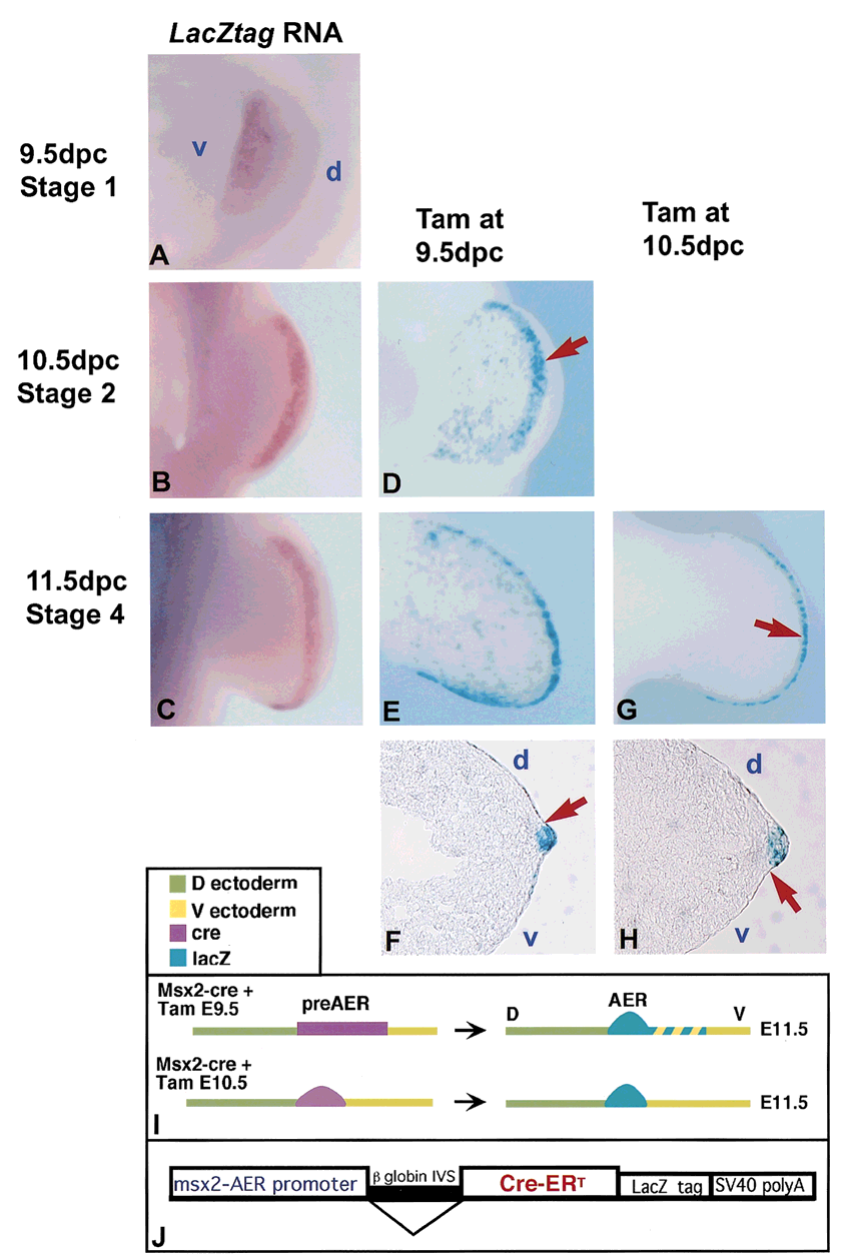

Figure 3. A border is present early at the dorsal AER margin $(A-C)$ RNA in situ analysis of CreER ${ }^{T}$ expression in Msx2-Cre$E R^{T}$ transgenic embryos using a lacZtag probe. Expression is seen in the ventral ectoderm at stage $1(A)$, at the distal-ventral margin at stage $2(B)$, and in the mature ridge at stage $4(C)$. Hindlimbs of embryos heterozygous for the Msx2-CreER ${ }^{T}$ transgene and R26R, following injection with $5.0 \mathrm{mg}$ of tam at $9.5 \mathrm{dpc}$ and dissection after 30-36 hr $(D)$ or 54-60 hr $(E, G)$. Labeled cells are seen in the ventral ectoderm and AER in stage $2(D)$ and stage $4(E)$ hindlimbs. $(F)$ Cryosection across the D/V axis of a representative limb as in $E$, showing dense AER labeling in addition to blue cells in the adjacent ventral ectoderm. The dorsal AER margin is sharply delineated $(D, F$, red arrow). Following injection with $5.0 \mathrm{mg}$ of tam at $10.5 \mathrm{dpc}$, embryos collected after 30-36 hours showed intense $\beta$-gal activity in the AER, with a few positive cells in the ventral ectoderm at the extreme anterior and posterior margins of the handplate $(G)$. Sectioning across the D/V axis shows labeled cells restricted within the AER $(\mathrm{H}$, arrow). In all sections, distal is to the right and dorsal is up. (d) Dorsal; (v) ventral. (I) Diagrammatic representation of fate-mapping results. Injection at $9.5 \mathrm{dpc}$, when transgene expression is throughout pre-AER, results in blue cells scattered within the ventral ectoderm and densely in the AER at $11.5 \mathrm{dpc}$ (top row). When tam is given at $10.5 \mathrm{dpc}$, transgene expression is restricted to the AER, and labeled cells at $11.5 \mathrm{dpc}$ are almost completely AER restricted. $(J)$ Schematic diagram of the Msx2-CreER ${ }^{T}$ construct. Cre-ER ${ }^{\mathrm{T}}$ was inserted into a transgene construct containing the $\beta$-globin intron, LacZtag, and SV40polyA, in which expression is driven by the Msx2-AER promoter. markers are not all committed to becoming part of the mature AER and do not maintain AER gene expression (Fig. 3I, top).

The autonomy of AER cells became apparent following administration of tam at later stages of limb development. Giving $5.0 \mathrm{mg}$ of tam at $10.0 \mathrm{dpc}$ resulted in blue cells in the ventral ectoderm and AER of stage 4 (11.5 dpc) hindlimb buds, as was described above for activation at $9.5 \mathrm{dpc}$ (data not shown). However, administration of tam at $10.5 \mathrm{dpc}$ (hindlimb stage 2, forelimb stage 3), followed by lacZ staining 30-36 hr later (11.5 dpc, limb stage 4-5), resulted in blue labeling predominantly in the AER in both forelimbs and hindlimbs, with a well-demarcated ventral and dorsal boundary (Fig. $3 \mathrm{G}, \mathrm{H}$, arrow). Only the most extreme anterior and posterior margins of the hand plate showed residual blue cells in the ventral ectoderm, with fewer such cells in forelimb as compared with hindlimb. This suggests that by $10.5 \mathrm{dpc}$, AER precursors have become committed to occupy the AER and no longer mix with ventral ectoderm, whereas pre-AER cells remaining in the ventral ectoderm do not maintain Msx2 expression (Fig. 3I, bottom). Furthermore, unlike the dorsal and D/V borders, the ventral boundary of the AER appears to be established after the AER becomes morphologically distinct.

\section{Misexpression of En1 throughout the AER inhibits limb formation}

By analogy to patterning in Drosophila wing imaginal discs (Irvine and Vogt 1997), bisection of the vertebrate AER into dorsal and ventral domains by a lineage restriction provides a basis for signaling interactions to occur between these two domains that could be involved in AER morphogenesis. So far, vertebrate En1 is the only known gene to be expressed in only one of the AER D/V domains. Furthermore, the loss-of-function mutant studies in mice have shown En1 is required for proper AER formation. If ventral versus dorsal domains within the AER are required for its proper formation and En1 controls specification of the ventral domain, then misexpression of En1 in the dorsal AER should disrupt formation, or stability of, the $\mathrm{D} / \mathrm{V}$ boundary and thereby should also disrupt AER formation, leading to limb abnormalities. To examine whether this is the case, En1 was misexpressed throughout the AER.

Of six Msx2-En1 founder mice produced, one (no. 86) showed a dramatic limb phenotype characterized by severe truncation of both hindlimbs and deformed paws with absent digits and less severe syndactyly and oligodactyly in the forelimbs. Two additional founders (nos. 25 and 95) had normal-appearing limbs, but when bred to wild-type females gave pups with a phenotype similar to that seen in line no. 86. One founder transmitted the transgene but the litter had no phenotype and embryos did not show transgene expression. Two other founders gave normal litters and were not analyzed further. Analysis of several litters from founders nos. 25, 86, and 95 demonstrated that lines nos. 86 and 25 showed the phenotype in $100 \%$ of transgenic offspring, whereas only 
$\sim 60 \%$ of the transgenic offspring from line no. 95 displayed limb defects. All three lines were fully viable and fertile. Although our studies have concentrated on line no. 86, a similar range of defects was seen in affected transgenic animals from all three lines.

Homozygous transgenics had a more severe phenotype than hemizygotes, but in both genotypes the forelimbs were less severely affected than the hindlimbs (Fig. 4A). Several litters of hemizygous and homozygous newborns ( $\mathrm{n}=25$ animals) were examined in detail by bone and cartilage analysis. In the forelimbs of the hemizygotes, the most common phenotype was loss of digits 3, 4 and/ or $5(69 \%)$ (Fig. 4, cf. C with B). Generation of only a single digit was seen in rare cases $(3 \%)$. The zeugopod was also affected with partial $(8 \%)$ or complete loss of the ulna $(8 \%)$. In cases of partial ulna loss, the proximal portion is preserved, and the radius is bowed. The hindlimbs of hemizygotes frequently had a nearly complete absence of the autopod, with one malformed digit consisting of cartilaginous fragments distal to the zeugopod (67\%) (Fig. 4, cf. F with E). Occasionally, extra partial digits were seen in both forelimbs $(10 \%)$ and hindlimbs $(13 \%)$, which did not show any preferential anterior-posterior localization (Fig. 4H, arrowheads). In addition, some hindpaws had ectopic digits protruding from the ventral handplate (Fig. 4I, arrow) or distal zeugopod (Fig. $4 \mathrm{~J}$, arrow) that contained poorly formed bony elements usually lost during processing ( $8 \%$ of limbs). Homozygous transgenics were overall more severely affected, with forelimbs having only $1-2$ digits $(70 \%)$, or truncation below the humerus (10\%, Fig. 4D). $20 \%$ had more mildly affected forelimbs, with only digits 4 and 5 malformed. The majority of homozygotes lacked hindlimbs, with only small fragments of the femur present $180 \%$, Fig. 4G). Some homozygotes (20\%) had a tibia and distal cartilaginous fragments, resembling the hemizygous phenotype.

\section{AER formation is perturbed when En1 is expressed throughout the AER}

The severe phenotype of the Mxs2-En1 homozygous mutants suggested that misexpression of En1 had perturbed
AER formation as it is reminiscent of the truncations produced in chick limbs following AER removal (Saunders 1948; Summerbell 1974). Early limbs buds were therefore examined for expression of the AER marker gene Fgf8. In stage 1 transgenic Msx2-En1 hemizygous limbs, Fgf8 was expressed normally in the ventral ectoderm of both forelimbs and hindlimbs (Fig. 5, cf. F and J to A). By stage 2, the expression domain of Fgf8 in the forelimbs and hindlimbs of Msx2-En1 hemizygous mutants showed irregular borders and an overall decrease in level as compared with wild types (Fig. 5, cf. G and $\mathrm{K}$ to B). Fgf8 expression in stage 3 forelimbs became discontinuous, with the posterior portion being more affected (Fig. 5, cf. H, arrow, and C). Hindlimb Fgf8 expression at stage 3 was more severely fragmented and showed clusters of expressing cells shifted dorsally or ventrally relative to the D/V margin (Fig. 5, cf. L, arrows, and C). Forelimbs and hindlimbs became notched with further development, with $F g f 8$ expression present only along those portions of the distal handplate that had maintained proximal-distal outgrowth (Fig. 5, cf. I and $\mathrm{M}$ with D). In addition, segments and patches of $F g f 8$ expression were seen anteriorly and at abnormal locations along the $\mathrm{D} / \mathrm{V}$ axis in some hindlimbs (Fig. 5, cf. $\mathrm{N}$ with $\mathrm{E}$ ). The more marked disruption of Fgf8 expression seen in hindlimbs versus forelimbs correlates with the more severe hindlimb defects that are seen at birth. Sections of stage 2-3 forelimb buds across the $\mathrm{D} / \mathrm{V}$ axis showed there was a range of AER phenotypes, from clearly visible but flattened ridges that contained patchy Fgf8 expression, to regions with no ridge or $F g f 8$ expression where limb outgrowth was reduced (not shown, see Fig. 6 for morphology).The large gaps in the handplate likely prefigure the missing bone elements seen in newborn paws, whereas small ectopic patches of ridge along the anterior margin could explain the occasional occurrence of ectopic digits.

In homozygotes, the hindlimb phenotype suggests early failure of AER formation. Although Fgf8 expression did initiate at stage $0.5 / 1$ in such hindlimbs, by stage 2 there was virtually no Fgf8 expression. As expected, hindlimb bud outgrowth was severely compromised by 10.5 dpc (data not shown).

Expression of the transgene was examined using a

Figure 4. Misexpression of En1 throughout the AER perturbs limb development. (A) Two-day-old mice hemizygous (center) or homozygous (right) for the Msx2-En1 transgene have severe limb deformities, as compared to a wild-type (left). Skeletal preparations of a wild type newborn mouse, showing the normal zeugopod, stylopod, and autopod $(B, E)$. Hemizygous transgenic showing loss of posterior digits $4-5$ of the forelimb $(C)$ and nearly complete absence of the autopod of the hindlimbs $(F)$. Severely affected homozygote with the forelimb truncated at the proximal stylopod $(D)$
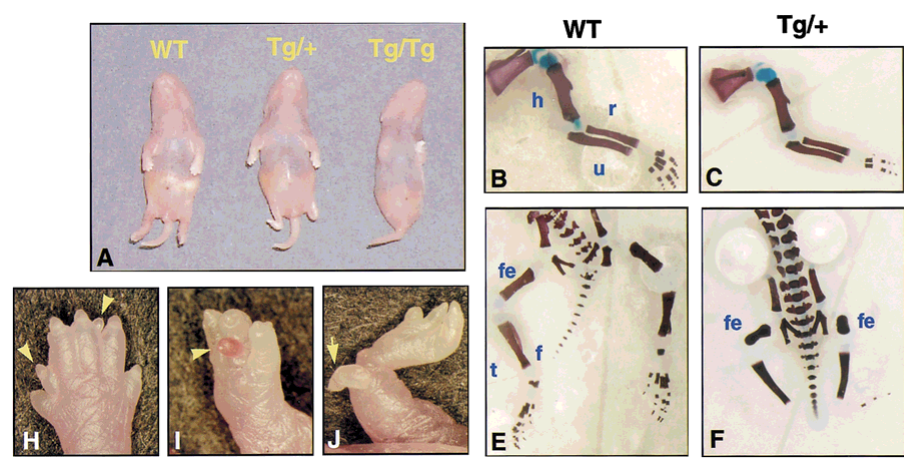

$\mathrm{Tg} / \mathrm{Tg}$

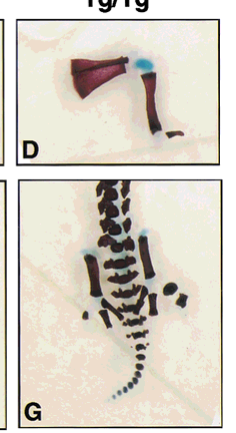

and truncation of hindlimbs at the proximal femur $(G)$. Ectopic outgrowths were seen infrequently and include extra digits within the plane of the handplate $(H$, arrowheads), protruding perpendicular to the ventral handplate $(I$, arrow), or from more proximal locations $(J$, arrow). (h) Humerus; (r) radius; (u) ulna; (fe) femur; (t) tibia; (f) fibula. 

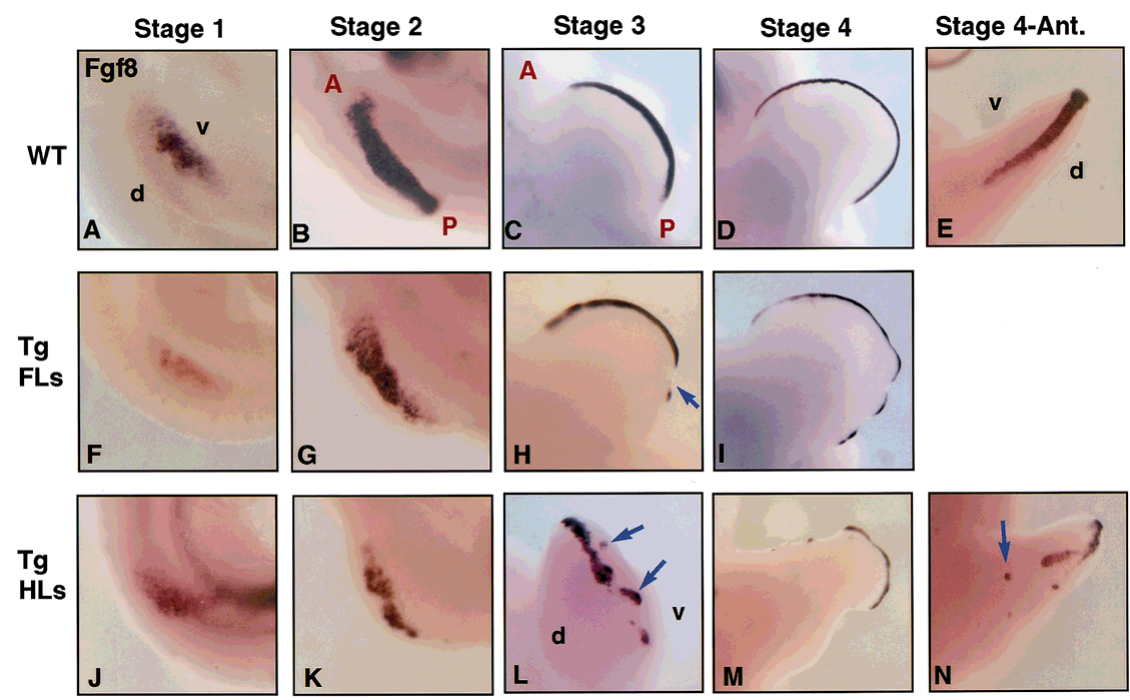

Lineage boundaries coordinate AER formation limb bud $(E)$. (d) Dorsal; (v) ventral; (A) anterior; $(\mathrm{P})$ posterior.

probe specific for the lac $Z$ fragment in the transgene in hemizygous embryos. The pattern was similar to that seen for $F g f 8$, with expression initiating at stage $0.5 / 1$ and becoming patchy and discontinuous by stage $2-3$ (data not shown). Transgenic embryos from line nos. 25 (in $100 \%$ ) and 95 (in 60\%) showed similar transgene and Fgf8 expression patterns and notching of the distal margin (data not shown). Consistent with loss of AER marker gene expression and distal limb notching, dysfunction of the AER was reflected by decreased expression of progress zone markers such as Fgf10, Evx1, and Jag2 underlying regions where $F g f 8$ was lost (data not shown). Expression of Shh in the zone of polarizing activity (ZPA) was similarly reduced in the notched posterior mesenchyme of transgenic limb buds (data not shown).

\section{AER borders are disrupted in Msx2-En1 mutants}

Both gene expression and fate mapping were used to examine changes in ectoderm specification and AER boundaries in hemizygous Msx2-En1 mutants. Forelimbs, in which AER formation is less severely perturbed, were examined in order to have some regions with morphological ridges to serve as a reference point. In forelimbs of wild-type $10.5 \mathrm{dpc}$ embryos (stage 3 limbs), the dorsal boundary of the AER and Fgf8/Msx2 expression is coincident with the distal limit of Wnt7a expression, whereas the mid-AER border corresponds to the distal limit of En1 expression (Fig. 6A,B). The region lacking both En1 and Wnt7a expression is the dorsal AER (Fig. 6B). In Msx2-En1 transgenic 10.5 dpc forelimb buds labeled for En1 (endogenous and transgenic) as well as Wnt7a, the distal boundary of expression of both genes was wavy instead of smooth (Fig. 6, cf. D and A). Sections across the D/V axis of such limb buds showed En1 expression in the ventral ectoderm and throughout the flattened AER (described previously), but surprisingly, Wnt7a expression was not adjacent to this aberrant ridge (Fig. 6E). In regions along the anterior-posterior (A/P) axis where there was no thickened ectoderm visible, Wnt7 $a$ expression was also shifted proximally away from the En1 domain (Fig. 6F). Thus, the dorsal border of the AER, characterized by an abrupt morphological change from columnar AER cells to cuboidal dorsal epithelium that express Wnt7a, is perturbed in Msx2-En1 mutant limbs such that Wnt7a is not expressed adjacent to the ridges that form. In addition, the ridges have wavy, rather than straight, dorsal and ventral borders.

The position of the $\mathrm{D} / \mathrm{V}$ border, as defined by endogenous En1 expression, was examined using lacZ expression from an En1 knock-in allele $\left(E n 1^{L k i}\right.$; Hanks et al. 1995; Matise and Joyner 1997). In wild-type 10.5-dpc forelimb buds, a rim of intense lac $Z$ staining in the AER is readily apparent at the distal margin (Fig. 6C). In 10.5 dpc embryos heterozygous for En1 $1^{L k i}$ and Msx2-En1, there did not appear to be significant $l a c Z$ staining at the distal margin and the distal border of expression was uneven (Fig. 6, cf. G with C). Sections across the D/V axis revealed that in some regions with flattened ridges, lacZ-expressing cells were not present in the ridge but were located more ventrally (Fig. $6 \mathrm{H}$ ), whereas in regions without an AER, lacZ expression extended to the distal tip (Fig. 6I).

One possible reason for the apparent shift in En1 expression relative to the position of the AER is that endogenous En1 expression is initiated normally at early pre-AER stages but then is lost distally in mutants. To address this and to determine the initial position of the $\mathrm{D} / \mathrm{V}$ border at $9.5 \mathrm{dpc}$, a similar analysis was performed in embryos heterozygous for $E n 1^{C k i}$, Msx2-En1, and the R26R reporter allele, thus marking cells that had expressed endogenous En1 before the transgenic misexpression of En1 perturbed limb development. In such 


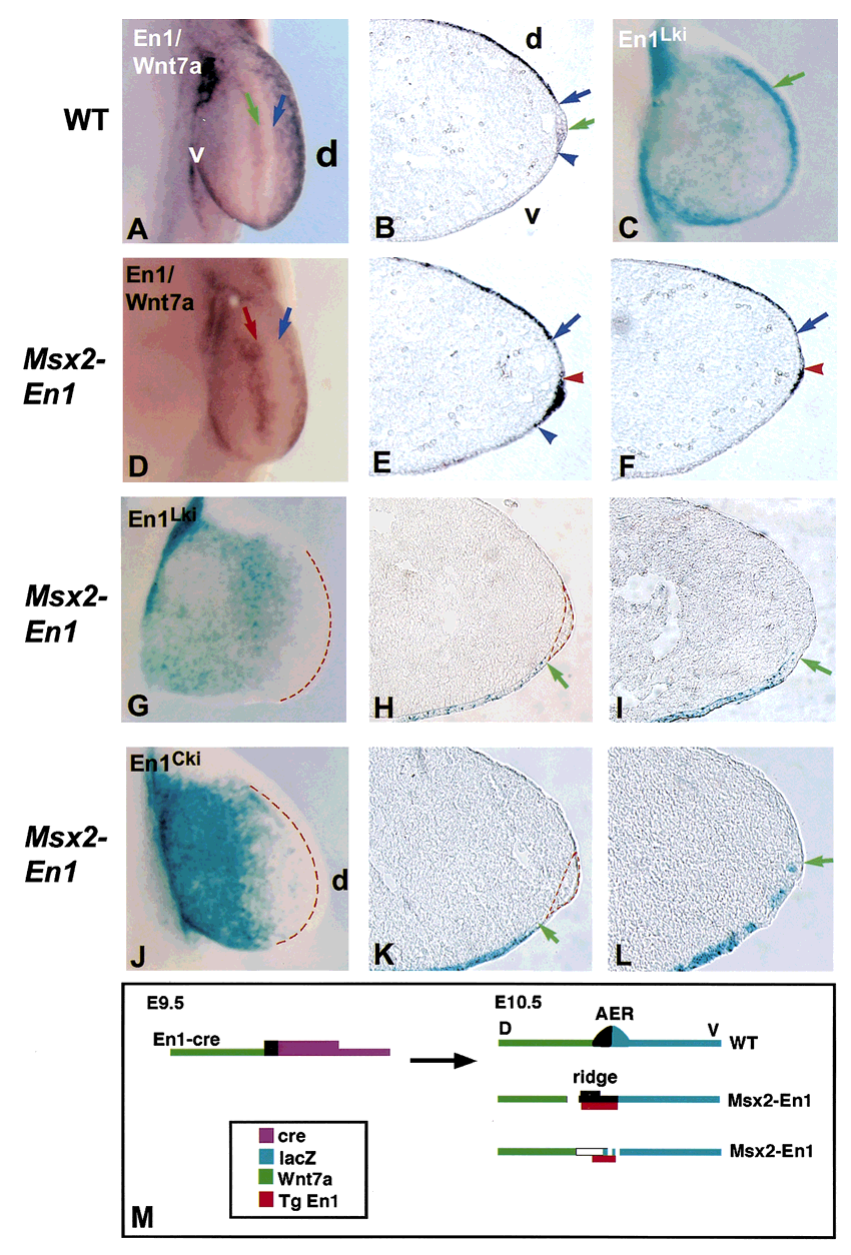

Figure 6. AER borders are disrupted in Msx2-En1 mutants. Forelimb buds of 10.5-pdc embryos labeled for Wnt7a and En1 RNA $(A, B, D-F)$ or for $\beta$-galactosidase $(C, G-L)$. In wild-type embryos in whole mount $(A)$ and in cross section $(B), E n 1$ is expressed ventrally up to the $\mathrm{D} / \mathrm{V}$ midline of the $\mathrm{AER}(A, B$, green arrow); Wnt7a is expressed in the dorsal ectoderm up to the dorsal margin of the $\operatorname{AER}\left(A, B\right.$, blue arrow). lac $Z$ expression in En1 $1^{L k i}$ embryos in seen in the ventral ectoderm and ventral half of the AER $\mid C$, green arrow). (D) In Msx2-En1 transgenic embryos, the distal limits of En1 (red arrow) and Wnt7a (blue arrow) no longer have smooth contours. Some regions show En1 expressed throughout a flattened ridge (E, between red and blue arrowheads). In other regions, no ridge is visible $(F)$. The distal limit of Wnt7a expression $(E, F$, blue arrow) is not adjacent to the shifted En1 domain $(E, F$, red arrowhead). lacZ staining in both $E n 1^{L k i} / M s x 2-E n 1(G-I)$ and $E_{n 1}{ }^{C k i} / R 26 R / M s \times 2-E n 1$ ( $\left.J-L\right)$ embryos has an irregular distal limit $(G, I)$ and lacks dense lac $Z$ staining at the limb bud margin (red broken line). In sections, ridges (outlined by red broken line) are no longer centered on the distal limit of endogenous En1 expression $(H$, green arrow). The distal limit of lacZ-positive cells in $E_{n} 1^{C k i} / R 26 R / M s \times 2-E n 1$ embryos is proximal ( $K$, green arrow) to a flattened ridge (outlined by red broken line), or reaches the distal margin $(L$, green arrow) in a region lacking an AER. $(M)$ Schematic showing disrupted ectoderm boundaries in Msx2-En1 mutant embryos. In wild-type limb buds (top right), the AER is centered on the distal limit of En1-expressing cells. In Msx2-En1 mutant embryos (middle right), in regions where a ridge is present the distal limit of $1 a c Z$ and $W n t 7 a$ are shifted proximally. In regions lacking a ridge (bottom right), transgenic En1 extends further distally than cells expressing endogenous En1, and Wnt7a is absent from cells adjacent to the ectopic En1. embryos, there was a lack of intense $1 a c Z$ staining at the distal margin (Fig. 6J), similar to En1 ${ }^{L k i} / M s x 2-E n 1$ embryos (Fig. 6G). Sections of limb buds revealed the expected spectrum of phenotypes in which flattened AERs could be distinguished in some regions, but other regions contained no ridge. In some regions where a ridge was present, the limit of lac $Z$ expression was proximal to it (Fig. 6K); in others blue cells were present at variable positions within the ventral portion of the ridge (not shown). Thus, in some regions of the Msx2-En1 limbs, a dorsally shifted AER had been induced containing cells that never expressed endogenous En1. In regions lacking a ridge, lacZ-expressing cells were interspersed with unlabeled cells near the distal extent of expression (Fig. 6L). These studies demonstrate that the dorsal and D/V borders of the AER, normally marked by the distal border of Wnt $7 a$ and of Cre expression from an endogenous En1 allele at $9.5 \mathrm{dpc}$, respectively, are jagged and abnormally positioned in Msx2-En1 transgenics (Fig. 6M).

\section{Discussion}

AER formation requires assembling widespread precursor cells into a compacted linear structure at the proper position along the $\mathrm{D} / \mathrm{V}$ axis of the embryo and maintenance of growth factor expression precisely in the definitive AER cells. Based on our experiments, we propose that cells of the dorsal and ventral pre-AER domains are pulled towards the lineage boundary at the dorsal margin of the pre-AER domain, which also provides a stable linear reference point for the assembling ridge (Fig. 7A). In addition, bidirectional constrictive pulling toward the $\mathrm{D} / \mathrm{V}$ border, which is regulated by En1, generates a dome-shaped AER with its definitive central peak (Fig. 7C). Consistent with this, the distinctive triangular morphology is not maintained and the AER flattens after the $\mathrm{D} / \mathrm{V}$ border is lost or if En1 is misexprssed in the dorsal AER. The borders that are then present between the mature AER and the adjacent ectoderm domains likely are important for maintaining AER position at the distal margin after the middle border is lost, as well as for providing the mechanical framework to generate a paddleshaped limb bud (Dahmann and Basler 1999; Hogan 1999). Finally, AER morphogenesis and gene expression are dependent on cell-cell interactions at the dorsal and $\mathrm{D} / \mathrm{V}$ borders, which are regulated, at least in part, by Wnts and En1. Cells in the ventral pre-AER that do not receive sufficient signaling lose AER specification and growth factor expression and become incorporated into the ventral ectoderm.

\section{Lineage relationships in limb ectoderm}

It has been proposed that compartment boundaries stabilize the position of patterning centers during morphogenesis, allowing for precise patterning of growing structures (Dahmann and Basler 1999). The fate-mapping experiments described here using Cre-mediated somatic recombination and retroviral cell labeling show that a 


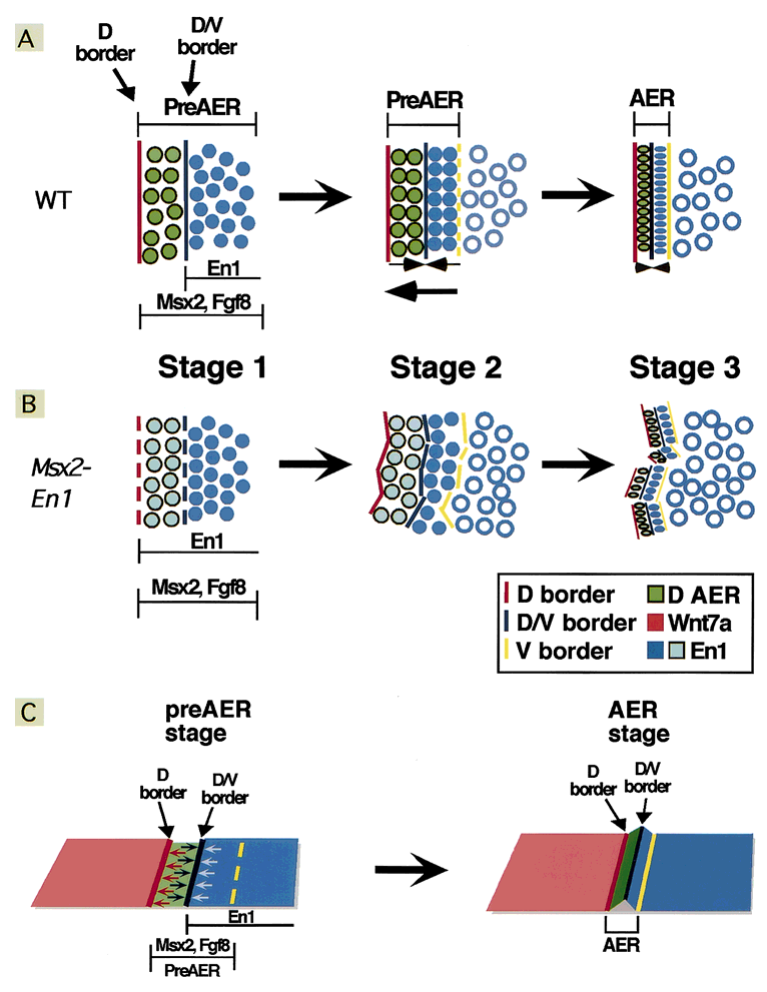

Figure 7. Two stable borders are required for AER formation. A schematic of AER assembly in wild-type $(A, C)$ and Msx2-En1 mutant $(B)$ embryos. In wild-type limb buds, AER precursors (solid blue and green circles) are initially distributed widely in ventral ectoderm $(A, l e f t)$. These pre-AER cells then assemble along the dorsal (D) AER border. A portion of these precursors are not incorporated into the AER and remain as ventral ectoderm (open blue circles) ( $A$, middle). The compacted, linear AER is generated as the entire domain shifts towards the D border concurrent with compression of the cells, symmetrically directed towards the $\mathrm{D} / \mathrm{V}$ border, through increases in cell height and density $(A, r i g h t, C)$. The ventral AER margin limits cell mixing after the mature AER has formed. In Msx2-En1 mutant embryos $(B)$, the $\mathrm{D}$ and $\mathrm{D} / \mathrm{V}$ borders are not stable. Cells attempt to assemble and compact along these displaced borders, resulting in a discontinuous, malaligned ridge $(B$, right $)$.

$\mathrm{D} / \mathrm{V}$ lineage boundary restricts cell movement within the AER during its formation and the period of its peak function. By transient activation of a tamoxifen-inducible Cre recombinase, we were able to mark cells of the pre-AER to demonstrate that a boundary exists between the preAER cells and the dorsal ectoderm, but not the ventral ectoderm and pre-AER, at the time of AER marker gene initiation. Induction of Cre when a fully differentiated AER was present showed that the AER becomes a self-contained cell population.

Our studies in mouse have shown that the ventral border is established after the AER begins to form and, importantly, that both the middle and dorsal borders form early but the middle border is transient. If the same is true in chick, then it is possible that the mixing seen within the ventral AER in the diI labeling studies (Altabef et al. 1997) was due to analyses done at slightly later stages as compared to the chick-quail transplantation studies (Michaud et al. 1997), in which there was a sharp $\mathrm{D} / \mathrm{V}$ border within the AER. Furthermore, our use of an inducible Cre recombinase in mouse enabled us to vary the times at which we initiated cell marking, permitting characterization of the location and dynamics of the multiple borders influencing AER formation.

Fate-mapping studies in the chick have attempted to address the lineage relationship of ventral ectoderm cells to the mature AER but were unable to resolve issues of early cell commitment. Using temporally and spatially regulated somatic recombination to study this question in mouse, we have shown that the initial population of pre-AER cells consists of cells not yet committed to an AER fate. As the ridge assembles, cell-cell interactions likely stabilize AER differentiation through positive regulatory signals, though precursors that don't receive sufficient signal may revert to ventral ectoderm (Fig. 7A). Our mouse fate mapping experiments using Msx2-Cre$E R^{T}$ indicate that the AER precursors are restricted to the ventral ectoderm at stage 1 . In contrast, diI labeling experiments in chick showed that some AER cells are located dorsally at an earlier stage (Altabef et al. 1997). Other studies suggest that dramatic shifts of ectoderm occur prior to limb outgrowth that most likely result in the pre-AER cells being localized to the ventral ectoderm at the time of AER marker gene induction and thus Cre initiation, in our studies (Geduspan and Solursh 1992; Michaud et al. 1997).

\section{Cellular interactions involving En1 and Wnts are important for AER formation}

To determine whether it is critical for En1 to be expressed only in the ventral AER, transgenic mice were generated that express En1 throughout the AER. In hemizygous transgenics with moderate levels of En1 in the dorsal AER, improperly aligned, fragmented AERs formed that likely reflect pre-AER cells trying to assemble along abnormal borders (Fig. 7B). Indeed, the D/V border marked by the distal limit of endogenous En1 was irregular at $10.5 \mathrm{dpc}$ and the AER in some regions was no longer centered on the position of the initial $\mathrm{D} / \mathrm{V}$ border, but was shifted dorsally. Wnt7a expression was also shifted, but proximally away from the dorsal border of the AER, showing that the dorsal AER boundary was perturbed and that signaling downstream of En1 can influence the fate of adjacent En1 negative dorsal cells. In homozygous Msx2-En1 transgenics, in which En1 is expressed at higher levels and possibly in a more homogeneous manner, AER gene expression is lost at the preAER stage, suggesting that signaling between distinct dorsal and ventral cells is required to maintain AER gene expression.

Formation of a ridge dorsal to the normal D/V border in Msx2-En1 hemizygous transgenics suggests that a dorsally shifted AER is being induced adjacent to the new En1 boundary. The repression of Wnt7a adjacent to En1 cells indicates that an early response to ectopic En1 is repression of Wnt7a, which is a characteristic of the normal dorsal AER. Fgf8, and the transgene itself 
through the Msx2 promoter, are likely induced in the new dorsal AER. The dorsally shifted transgene-derived En1 would then propagate these interactions at variable rates in different areas along the $\mathrm{A} / \mathrm{P}$ axis, causing unstable borders that result in malaligned and fragmented ridges (Fig. 7B). The nearly complete failure of AER formation in Msx2-En1 homozygous transgenics could be due to homogeneous high levels of En1 in the dorsal AER inhibiting signaling interactions at the D/V boundary, or because more complete and rapid repression of Wnt7a and other Wnt genes in dorsal ectoderm abolishes the movements required for ridge assembly.

Previous studies showed that retroviral misexpression of En1 randomly throughout the chick limb results in AER loss and ectopic AER formation (Laufer et al. 1997; Logan et al. 1997; Rodriguez-Esteban et al. 1997). It was proposed that the two phenotypes were due to uniform En1 expression across the D/V border or patchy expression in the dorsal ectoderm, respectively (Laufer et al. 1997; Logan et al. 1997; Rodriguez-Esteban et al. 1997). However, the replication-competent retrovirus used infects randomly and spreads with time, so the various phenotypes could not be conclusively correlated with a particular pattern of ectopic En1 expression. En1 was hypothesized to act through repression of $R$-fng although the two genes are coexpressed in the ventral AER (Laufer et al. 1997; Rodriguez-Esteban et al. 1997). Furthermore, $R$-fng expression can barely be detected in mouse limb buds and null mutants have normal limbs (Moran et al. 1999). The expression pattern of $R$ - $f n g$ in chick argues against it being an important molecule in boundary determination and AER formation, because the distal limit is located at the ventral border of the AER (Laufer et al. 1997; Rodriguez-Esteban et al. 1997, Moran et al. 1999), which we have demonstrated is only present after AER formation. Our studies show that the phenotypes generated by random retroviral En1 misexpression can be produced simply by specific expression of En1 in the dorsal AER.

The ectopic AERs that form late in En1 mutants are located at the distal border of ectopic ventral Wnt7a expression and are absent from $W n t 7 a^{-/-} / E n 1^{-/-}$double mutants (Cygan et al. 1997; Loomis et al. 1998). This suggests that during normal AER formation, Wnt molecules, including $W n t 7 a$, likely play a role in forming a ridge of cells at the dorsal border. Wnt $3 a$ has been shown in chick to be capable of causing ectopic ridges when misexpressed (Kengaku et al. 1998), and factors that have been shown to act downstream of Wnt3a are critical for mouse AER development (Galceran et al. 1999). Although Wnt3a is not expressed in mouse limb ectoderm, other Wnts are (Parr et al. 1993), and these may have overlapping functions with Wnt7a or be regulated by WNT7a.

Consistent with our misexpression studies demonstrating a role for En1 in generating a dome-shaped AER, En1 null limb buds have broad, flattened ridges. Furthermore, En1 ${ }^{C k i}$-based fate mapping has revealed that the $\mathrm{D} / \mathrm{V}$ border is not sharply defined in En1 mutants (unpubl.). Although En1 is clearly involved in maintaining a sharp D/V border and in signaling across the D/V border, other genes must act with En1 to define the ventral AER, as Wnt $7 a^{-/-} / E n 1^{-/-}$double mutants have an AER. The relatively normal AER formed in $W n t 7 a^{-/-}$and $W n t 7 a^{-/-}$ $/ E n 1^{-/-}$double mutants could also be accounted for by biological redundancy at the level of borders, and one sharp border might be sufficient to form a relatively normal AER. Genes responsible for setting up the initial limb D/V axis remain to be identified and may be responsible for the defects seen in chick mutants such as limbless, in which defective specification of the $\mathrm{D} / \mathrm{V}$ axis includes an absence of En1 expression, as well as of Fgf8 (Grieshammer et al. 1996; Ros et al. 1996).

\section{AER formation requires stable boundaries}

In Drosophila limb development, organizers promoting outgrowth are generated through cell-cell interactions at perpendicularly oriented $\mathrm{D} / \mathrm{V}$ and $\mathrm{A} / \mathrm{P}$ compartment borders within epithelial imaginal discs. We have shown that vertebrate AER formation requires two lineage borders oriented parallel to each other. The different arrangement of boundaries could reflect the unique requirements for generating and maintaining signaling centers within a planar epithelial sheet in fly versus in a budding structure with multiple tissue layers in vertebrates. As limb ectoderm and mesoderm undergo dramatic expansion during development, it is essential that these two tissues remain appropriately juxtaposed and the AER stays localized at the distal tip during limb outgrowth.

Based on our results, we propose a model for vertebrate AER development in which prior to limb outgrowth at $9.0 \mathrm{dpc}$, the ectoderm is divided into domains of lineage restriction that express selector-type genes that have yet to be identified. At 9.0 dpc, Fgf10 induces expression of AER genes such as Fgf8 and Msx2 (Michaud et al. 1997; Bell et al. 1998; Loomis et al. 1998; Min et al. 1998; Sekine et al. 1999) in a population of AER precursors in ectoderm ventral to the dorsal lineage restriction. At 9.5-10.0 dpc, signaling from the dorsal ectoderm to the pre-AER and interactions within the ridge, controlled in part by En1, act to maintain expression of AER genes and to promote formation of a ridge with its apex at the $\mathrm{D} / \mathrm{V}$ border. After $11.5 \mathrm{dpc}$ when the D/V border is lost, the AER flattens and eventually regresses. The involvement of two borders in AER formation likely reflects the complexity of assembling a signaling center with precise topographic requirements concurrent with tissue outgrowth and patterning.

\section{Materials and methods}

\section{Construction of transgenic vectors}

The vector for transgenic misexpression was generated using a modified pKS bluescript backbone (Stratagene), in which the SacI site in the polylinker had been changed to SalI (C. Logan and A. Joyner, unpubl.). A cDNA encoding a Cre-ER ${ }^{\mathrm{T}}$ fusion protein, kindly provided by P. Chambon (Feil et al. 1996), was 
excised from pCre-ER ${ }^{\mathrm{T}}$ (using EcoRI digestion and the remaining plasmid containing a $\beta$-globin intron and poly(A) sequence was recircularized to form pSG6. The $\beta$-globin intron and SV40poly(A) on an 830-bp ClaI-XbaI fragment from pSG6 was inserted into the ClaI and $\mathrm{XbaI}$ sites, respectively, of pKS (SalISalI) to create pKS-IVS-poly(A). A SacI-KpnI fragment containing a polylinker and 825-bp lacZtag, kindly provided by D. Epstein (Epstein et al. 1996), was blunt-end ligated into the EcoRI site of pKS-IVS-poly(A) to create PEV II.

A 520-bp Msx2 AER-specific promoter on an EcoRI fragment, kindly provided by R. Maxson (Liu et al. 1994), was blunt-end ligated into the ClaI site of PEVII, creating Msx2-EV. The EcoRI fragment containing $\mathrm{CreER}^{\mathrm{T}}$ was then subcloned into the SnaBI site of Msx2-EV to create the final construct Msx2-CreER ${ }^{\mathrm{T}}$. Similarly, the ApaI fragment of an En1 cDNA (Joyner et al. 1985) was blunt-end ligated into the SnaBI site to generate Msx2-En1. For both Msx2-CreER ${ }^{T}$ and Msx2-En1, the transgene construct was purified from the vector sequences by cleaving the plasmid with SalI, and transgenic animals were generated by zygote injection (Hogan et al. 1994) in Swiss Webster mice.

Transgenic Msx2-CreER ${ }^{T}$ and Msx2-En1 mice and embryos were identified by phenotype and/or PCR on proteinase K-digested yolk sacs or tails. PCR was performed using upstream primers for either CreER ${ }^{\mathrm{T}}\left(5^{\prime}\right.$-CACTTTGATCCACCTGATGG$\left.3^{\prime}\right)$ or En1 (5'-GAGTTCCAGGCAAACCG-3') and a downstream primer against the $1 a c Z$ tag $\left(5^{\prime}\right.$-TACCACAGCGGATGGTTCGG-3'), which amplified DNA fragments of $420 \mathrm{bp}$, and $350 \mathrm{bp}$, respectively.

\section{UBM injection of retrovirus}

Virus preparation and animal surgery were performed as described previously (Olsson et al. 1997; Liu et al. 1998; Gaiano et al. 1999; Turnbull 1999). Viral stocks of pNK-lacZ (Gaiano et al. 1996 ) at $5 \times 10^{7} \mathrm{cfu} / \mathrm{ml}$ were diluted 1:20 in L15 media (Cellgro) and supplemented with polybrene at a final concentration of 80 $\mu \mathrm{g} / \mathrm{ml}$. Virus solution $(-0.5-1.0 \mu \mathrm{l})$ was injected into the amniotic cavity of 8.5 -dpc embryos. lacZ-labeled cell clusters selected for sectioning at both $10.5 \mathrm{dpc}$ and $11.5 \mathrm{dpc}$ contained at least six and, on average, eight cells.

\section{Fate mapping using Cre-expressing mice}

The En1-Cre knock-in (En1 $\left.{ }^{C k i}\right)$ construct was generated by inserting the Cre-recombinase gene cassette (Sauer and Henderson 1990) into a previously described En1 knock-in vector (Hanks et al. 1995, 1998; Broccoli et al. 1999) and electroporated into R1 ES cells. After germ-line transmission the neomycin cassette was removed by crossing to a transgenic mouse line expressing Cre-recombinase constitutively (Schwenk et al. 1995).

Proteinase K-digested DNA from yolk sacs or tails was genotyped by PCR using the upstream primer $\left(5^{\prime}\right.$-TAAAGATATCTCACGTACTGACGGTG-3') and the downstream primer (5'TCTCTGACCAGAGTCATCCTTAGC-3'), which amplified a band of $300 \mathrm{bp}$. Rosa26Reporter (R26R) mice were kindly provided by P. Soriano and genotyped as described (Soriano 1999).

Tamoxifen (Sigma T-5648) was dissolved in corn oil (Sigma $\mathrm{C}-8267)$ at $37^{\circ} \mathrm{C}$ for several $\mathrm{hr}$ with periodic vortexing to a final concentration of $20 \mathrm{mg} / \mathrm{ml}$. The tam solution was stored protected from light at $4^{\circ} \mathrm{C}$. Intraperitoneal injections of 5.0-10.0 $\mathrm{mg}$ were administered to the pregnant female mice at 8.5-10.5 dpc. For the timing of tam injections, the morning on which the vaginal plug was detected was designated as $0.5 \mathrm{dpc}$. Injections done in the evening were considered to have advanced by $0.5 \mathrm{~d}$.
Embryonic limb buds were staged according to the morphological criteria first described by Wanek et al. (1989), and modified by Bell et al. (1998) and Loomis et al. (1998).

\section{Whole-mount $\beta$-galactosidase histochemistry and RNA in situ analysis}

Embryos for in situ analysis were dissected in PBS and fixed overnight in $4 \%$ paraformaldehyde at $4^{\circ} \mathrm{C}$. The probes used were to En1 (Wurst et al. 1994), Wnt7a (Parr and McMahon 1995), and Fgf8 (Crossley and Martin 1995). RNA in situ analysis was performed essentially as described (Matise and Joyner 1997), except NBT $(4.5 \mu \mathrm{l} / \mathrm{ml}) / \mathrm{BCIP}(3.5 \mu \mathrm{l} / \mathrm{ml})$ in NTMT was used as the AP substrate. For ectoderm analysis, Proteinase K treatment consisted of $0.2 \mu \mathrm{g} / \lambda \mathrm{l}$ for $5 \mathrm{~min}$ at $37^{\circ} \mathrm{C}$. Embryos for $\beta$-galactosidase analysis were fixed in $4 \%$ paraformaldehyde/ PBS for $30 \mathrm{~min}-1 \mathrm{hr}$, depending on age, and processed as described (Liu et al. 1998).

\section{Histology}

Limbs from UBM-guided injection of retrovirus to be cryosectioned were incubated overnight at $4^{\circ} \mathrm{C}$ in $15 \%$ sucrose/PBS Samples were then embedded in a solution of $7.5 \%$ gelatin $/ 15 \%$ sucrose in a $0.12 \mathrm{M}$ phosphate buffer $(\mathrm{pH} 7.4)$ and frozen in isopentane cooled to $-55^{\circ} \mathrm{C}$ with dry ice. Samples were sectioned in the D/V plane at $8 \mu \mathrm{m}$. Embryos from whole-mount RNA in situ or $\beta$-gal analysis were immersed overnight in $15 \%$ sucrose followed by $30 \%$ sucrose for several hr. The embryos were then embedded in OCT and cut at 6-8 $\mu \mathrm{m}$.

For skeletal analysis, newborn pups were incubated overnight in $1 \mathrm{M} \mathrm{NaCl}$ at $37^{\circ} \mathrm{C}$ to loosen skin, rinsed for $24 \mathrm{hr}$ with PBS prior to removal of skin, and then processed as described (Lufkin et al. 1992).

\section{Acknowledgments}

We thank K. Losos and the Skirball Transgenic Facility for assistance with transgenic mouse production. We also thank G. Martin, A. McMahon, R. Maxson, and P. Chambon for sharing plasmids; A. Nagy for the R1 cells; K. Rajewski for the constitutive Cre expressing mouse line; and P. Soriano for the Rosa26Reporter mouse line. N. Gaiano, M. McCarthy, and D. Epstein generously provided plasmids, advice, and assistance. We are also grateful to A. Schier for comments and review of the manuscript. A.L.J. is a Howard Hughes Investigator. C.A.L receives support from a Career Development Award, Dermatology Foundation, and a Basil O'Connor Award, March of Dimes. D.H.T receives partial support from NIH grants N538461 and HL62334. A.L.J. and W.W. received support from HFSP.

The publication costs of this article were defrayed in part by payment of page charges. This article must therefore be hereby marked "advertisement" in accordance with 18 USC section 1734 solely to indicate this fact.

\section{References}

Altabef, M., J.D. Clarke, and C. Tickle. 1997. Dorso-ventral ectodermal compartments and origin of apical ectodermal ridge in developing chick limb. Development 124: 45474556.

Bell, S.M., C.M. Schreiner, and C.M. Scott. 1998. The loss of ventral ectoderm identity correlates with the inability to form an AER in the legless hindlimb bud. Mech. Devel. 74: 41-50. 
Brocard, J., X. Warot, O. Wendling, N. Messaddeq, J.L. Vonesch, P. Chambon, and D. Metzger. 1997. Spatio-temporally controlled site-specific somatic mutagenesis in the mouse. Proc. Nat1. Acad. Sci. 94: 14559-14563.

Broccoli, V., E. Boncinelli, and W. Wurst. 1999. The caudal limit of Otx2 expression positions the isthmic organizer. Nature 401: 164-168.

Chen, H., Y. Lun, D. Orchinnikov, H. Kokubo, K.C. Oberg, C.V. Pepicelli, L. Gan, B. Lee, and R.L. Johnson. 1998. Limb and kidney defects in Lmxlb mutant mice suggest an involvement of LMX1B in human nail patella syndrome. Nat. Genet. 19: 51-55.

Cohn, M.J., J.C. Izpisua-Belmonte, H. Abud, J.K. Heath, and C. Tickle. 1995. Fibroblast growth factors induce additional limb development from the flank of chick embryos. Cell 80: 739-746.

Crossley, P.H. and G.R. Martin. 1995. The mouse Fgf8 gene encodes a family of polypeptides and is expressed in regions that direct outgrowth and patterning in the developing embryo. Development 121: 439-451.

Crossley, P.H., G. Minowada, C.A. MacArthur, and G.R. Martin. 1996. Roles for FGF8 in the induction, initiation, and maintenance of chick limb development. Cell 84: 127-136.

Cygan, J.A., R.L. Johnson, and A.P. McMahon. 1997. Novel regulatory interactions revealed by studies of murine limb pattern in Wnt-7a and En-1 mutants. Development 124: 5021-5032.

Dahmann, C. and K. Basler. 1999. Compartment boundaries: At the edge of development. Trends Genet. 15: 320-326.

Danielian, P.S., D. Muccino, D.H. Rowitch, S.K. Michael, and A.P. McMahon. 1998. Modification of gene activity in mouse embryos in utero by a tamoxifen-inducible form of Cre recombinase. Curr. Biol. 8: 1323-1326.

Davis, C.A., D.P. Holmyard, K.J. Millen, and A.L. Joyner. 1991. Examining pattern formation in mouse, chicken and frog embryos with an En-specific antiserum. Development 111: 287-298.

Epstein, D.J., E. Marti, M.P. Scott, and A.P. McMahon. 1996. Antagonizing cAMP-dependent protein kinase A in the dorsal CNS activates a conserved Sonic hedgehog signaling pathway. Development 122: 2885-2894.

Feil, R., J. Brocard, B. Mascrez, M. LeMeur, D. Metzger, and P. Chambon. 1996. Ligand-activated site-specific recombination in mice. Proc. Natl. Acad. Sci. 93: 10887-10890.

Gaiano, N., M. Allende, A. Amsterdam, K. Kawakami, and N. Hopkins. 1996. Highly efficient germ-line transmission of proviral insertions in zebrafish. Proc. Natl. Acad. Sci. 93: $7777-7782$.

Gaiano, N., J.D. Kohtz, D.H. Turnbull, and G. Fishell. 1999. A method for rapid gain-of-function studies in the mouse embryonic nervous system. Nat. Neurosci. 2: 812-819.

Galceran, J., I. Farinas, M.J. Depew, H. Clevers, and R. Grosschedl. 1999. Wnt3a-/--like phenotype and limb deficiency in Lef1 $1^{(-/)}$Tcf $^{(-/-)}$mice. Genes \& Dev. 13: 709-717.

Geduspan, J.S. and M. Solursh. 1992. Cellular contribution of the different regions of the somatopleure to the developing limb. Develop. Dyn. 195: 177-187.

Grieshammer, U., G. Minowada, J.M. Pisenti, U.K. Abbott, and G.R. Martin. 1996. The chick limbless mutation causes abnormalities in limb bud dorsal-ventral patterning: implications for the mechanism of apical ridge formation. Development 122: 3851-3861.

Hanks, M., W. Wurst, L. Anson-Cartwright, A.B. Auerbach, and A.L. Joyner. 1995. Rescue of the En-1 mutant phenotype by replacement of En-1 with En-2. Science 269: 679-682.

Hanks, M.C., C.A. Loomis, E. Harris, C.-X. Tong, L.A. Anson-
Cartwright, A. Auerbach, and A.L. Joyner. 1998. Drosophila engrailed can substitute for mouse Engrailed1 function in mid-hindbrain, but not limb development. Development 125: 4521-4530.

Hogan, B.L. 1999. Morphogenesis. Cell 96: 225-233.

Hogan, B., R. Beddington, F. Constantini, and E. Lacy. 1994. Manipulating the mouse embryo. Cold Spring Harbor Laboratory Press, Cold Spring Harbor, New York.

Irvine, K.D. and T.F. Vogt. 1997. Dorsal-ventral signaling in limb development. Curr. Opin. Cell Biol. 9: 867-876.

Joyner, A.L., T. Kornberg, K.G. Coleman, D.R. Cox, and G.R. Martin. 1985. Expression during embryogenesis of a mouse gene with sequence homology to the Drosophila engrailed gene. Cell 43: 29-37.

Kengaku, M., J. Capdevila, C. Rodriguez-Esteban, J. de la Pena, R.J. Johnson, J.C. Izpisua Belmonte, and C.J. Tabin. 1998. Distinct Wnt pathways regulating AER formation and dorsoventral polarity in the chick limb bud. Science 280: 12741277.

Laufer, E., R. Dahn, O.E. Orozco, C.Y. Yeo, J. Pisenti, D. Henrique, U.K. Abbott, J.F. Fallon, and C. Tabin. 1997. Expression of Radical fringe in limb-bud ectoderm regulates apical ectodermal ridge formation. Nature 386: 366-373.

Liu, A., A.L. Joyner, and D.H. Turnbull. 1998. Alteration of limb and brain patterning in early mouse embryos by ultrasoundguided injection of Shh-expressing cells. Mech. Devel. 75: 107-115.

Liu, Y.H., L. Ma, L.Y. Wu, W. Luo, R. Kundu, F. Sangiori, M.L. Snead, and R. Maxson. 1994. Regulation of the Msx2 homeobox gene during mouse embryogenesis: a transgene with $439 \mathrm{bp}$ of $5^{\prime}$ flanking sequence is expressed exclusively in the apical ectodermal ridge of the developing limb. Mech. Develop. 48: 187-197.

Logan, C., A. Hornbruch, I. Campbell, and A. Lumsden. 1997. The role of Engrailed in establishing the dorsoventral axis of the chick limb. Development 124: 2317-2324.

Loomis, C.A., E. Harris, J. Michaud, W. Wurst, M. Hanks, and A.L. Joyner. 1996. The mouse Engrailed-1 gene and ventral limb patterning. Nature 382: 360-363.

Loomis, C.A., R.A. Kimmel, C.X. Tong, J. Michaud, and A. Joyner. 1998. Analysis of the genetic pathway leading to formation of ectopic apical ectodermal ridges in mouse Engrailed-1 mutant limbs. Development 125: 1137-1148.

Lufkin, T., M. Mark, C.P. Hart, P. Dolle, M. LeMeur, and P. Chambon. 1992. Homeotic transformation of the occipital bones of the skull by ectopic expression of a homeobox gene. Nature 359: 835-841.

Mahmood, R., J. Bresnick, A. Hornbruch, C. Mahony, N. Morton, K. Colquhoun, P. Martin, A. Lumsden, C. Dickson, and I. Mason. 1995. A role for FGF-8 in the initiation and maintenance of vertebrate limb bud outgrowth. Curr. Biol. 5: 797-806.

Martin, G.R. 1998. The roles of FGFs in the early development of vertebrate limbs. Genes \& Dev. 12: 1571-1586.

Matise, M.P. and A.L. Joyner. 1997. Expression patterns of developmental control genes in normal and Engrailed-1 mutant mouse spinal cord reveal early diversity in developing interneurons. J. Neurosci. 17: 7805-7816.

Michaud, J.L., F. Lapointe, and N.M. Le Douarin. 1997. The dorsoventral polarity of the presumptive limb is determined by signals produced by the somites and by the lateral somatopleure. Development 124: 1453-1463.

Milaire, J. 1974. Histochemical aspects of organogenesis in vertrebrates. Part I. The skeletal system. Limb morphogenesis. The sense organs. In Handbuch der histochemie, pp. 38-60. Gustav Fischer Verlag, Stuttgart, Germany. 
Min, H., D.M. Danilenko, S.A. Scully, B. Bolon, B.D. Ring, J.E. Tarpley, M. DeRose, and W.S. Simonet. 1998. Fgf-10 is required for both limb and lung development and exhibits striking functional similarity to Drosophila branchless. Genes \& Devel. 12: 3156-3161.

Moran, J.L., J.M. Levorse, and T.F. Vogt. 1999. Limbs move beyond the radical fringe. Nature 399: 742-743.

Niswander, L. 1997. Limb mutants: What can they tell us about normal limb development? Curr. Opin. Genet. Devel. 7: 530-536.

Olsson, M., K. Campbell, and D.H. Turnbull. 1997. Specification of mouse telencephalic and mid-hindbrain progenitors following heterotopic ultrasound-guided embryonic transplantation. Neuron 19: 761-772.

Parr, B.A. and A.P. McMahon. 1995. Dorsalizing signal Wnt-7a required for normal polarity of D-V and A-P axes of mouse limb. Nature 374: 350-353.

Parr, B.A., M.J. Shea, G. Vassileva, and A.P. McMahon. 1993. Mouse Wnt genes exhibit discrete domains of expression in the early embryonic CNS and limb buds. Development 119: $247-261$.

Riddle, R.D., M. Ensini, C. Nelson, T. Tsuchida, T.M. Jessell, and C. Tabin. 1995. Induction of the LIM homeobox gene Lmx1 by WNT7a establishes dorsoventral pattern in the vertebrate limb. Cell 83: 631-640.

Rodriguez-Esteban, C., J.W. Schwabe, J. De La Pena, B. Foys, B. Eshelman, and J.C. Belmonte. 1997. Radical fringe positions the apical ectodermal ridge at the dorsoventral boundary of the vertebrate limb. Nature 386: 360-366.

Ros, M.A., A. Lopez-Martinez, B.K. Simandl, C. Rodriguez, J.C. Izpisua Belmonte, R. Dahn, and J.F. Fallon. 1996. The limb field mesoderm determines initial limb bud anteroposterior asymmetry and budding independent of sonic hedgehog or apical ectodermal gene expressions. Development 122: 2319-2330.

Sanes, J.R., J.L. Rubenstein, and J.F. Nicolas. 1986. Use of a recombinant retrovirus to study post-implantation cell lineage in mouse embryos. EMBO T. 5: 3133-3142.

Sauer, B. and N. Henderson. 1990. Targeted insertion of exogenous DNA into the eukaryotic genome by the Cre recombinase. New Biol. 2: 441-449.

Saunders, J.W., Jr. 1948. The proximo-distal sequence of the origin of the parts of the chick wing and the role of th ectoderm. J. Exp. Zool. 108: 363-404.

Schwenk, F., U. Baron, and K. Rajewsky. 1995. A cre-transgenic mouse strain for the ubiquitous deletion of loxP-flanked gene segments including deletion in germ cells. Nucleic Acids Res. 23: 5080-5081.

Sekine, K., H. Ohuchi, M. Fujiwara, M. Yamasaki, T. Yoshizawa, T. Sato, N. Yagishita, D. Matsui, Y. Koga, N. Itoh, and S. Kato. 1999. Fgf10 is essential for limb and lung formation. Nat. Genet. 21: 138-141.

Soriano, P. 1999. Generalized lacZ expression with the ROSA26 Cre reporter strain. Nat. Genet. 21: 70-71.

Summerbell, D. 1974. A quantitive analysis of the effect of excision of the AER from the chick limb-bud. J. Embryol. Exp. Morph. 32: 651-660.

Tickle, C. and M. Altabef. 1999. Epithelial cell movements and interactions in limb, neural crest and vasculature. Curr. Opin. Genet. Dev. 9: 455-460.

Turnbull, D.H. 1999. In utero ultrasound backscatter microscopy of early stage mouse embryos. Comput. Med. Imaging Graph. 23: 25-31.

Vargesson, N., J. Clarke, K. Vincent, C. Coles, and L. Wolpert. 1997. Cell fate in the chick limb bud and relationship to gene expression. Development 124: 1909-1918.
Vogel, A., C. Rodriguez, W. Warnken, and J.C. Izpisua Belmonte. 1995. Dorsal cell fate specified by chick Lmx1 during vertebrate limb development. Nature 378: 716-720.

Vogel, A., C. Rodriguez, and J.C. Izpisua-Belmonte. 1996. Involvement of FGF-8 in initiation, outgrowth and patterning of the vertebrate limb. Development 122: 1737-1750.

Wanek, N., K. Muneoka, G. Holler-Dinsmore, R. Burton, and S.V. Bryant. 1989. A staging system for mouse limb development. J. Exp. Zool. 249: 41-49.

Wurst, W., A.B. Auerbach, and A.L. Joyner. 1994. Multiple developmental defects in Engrailed-1 mutant mice: An early mid-hindbrain deletion and patterning defects in forelimbs and sternum. Development 120: 2065-2075.

Zeller, R. and D. Duboule. 1997. Dorso-ventral limb polarity and origin of the ridge: On the fringe of independence? Bioessays 19: $541-546$.

Zinyk, D.L., E.H. Mercer, E. Harris, D.J. Anderson, and A.L. Joyner. 1998. Fate mapping of the mouse midbrain-hindbrain constriction using a site-specific recombination system. Curr. Biol. 8: 665-668. 


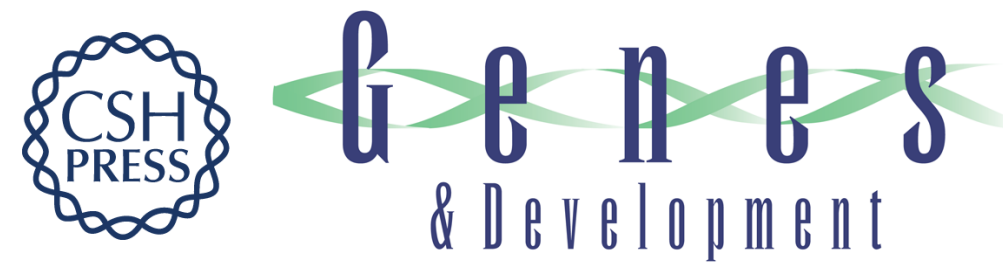

\section{Two lineage boundaries coordinate vertebrate apical ectodermal ridge formation}

Robin A. Kimmel, Daniel H. Turnbull, Veronique Blanquet, et al.

Genes Dev. 2000, 14:

Access the most recent version at doi:10.1101/gad.14.11.1377

References This article cites 61 articles, 24 of which can be accessed free at: http://genesdev.cshlp.org/content/14/11/1377.full.html\#ref-list-1

License

Email Alerting

Service

Receive free email alerts when new articles cite this article - sign up in the box at the top right corner of the article or click here.

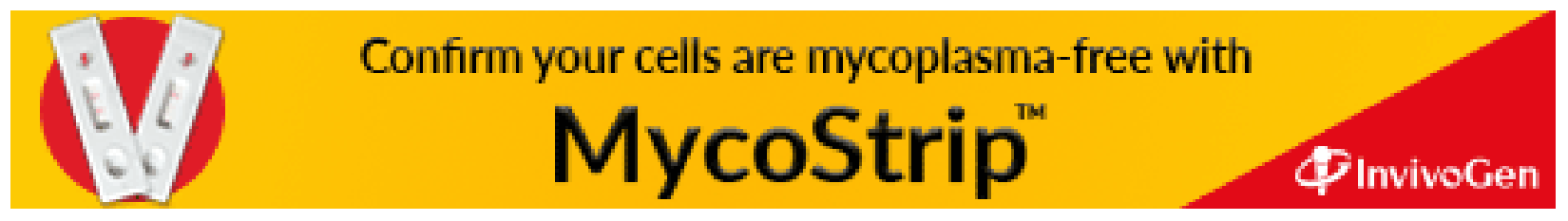

